\title{
Defining the Term "Argument"
}

\author{
P. CHITTLEBOROUGH University of Adelaide \\ M.E. NEWMAN
}

Key Words: Argument, definition, informal logic, human factors.

\begin{abstract}
Informal logic has expanded the concept of an 'argument' beyond that presented traditionally by formal logicians - to include arguments as encountered in 'real-life". Existent definitions of argument structure are argued to be inadequate by failing to fully recognise that, ultimately, arguments have a human source. Accordingly, a new definition is proposed which appeals to relevant cognitive and behavioural factors. The definition retains some traditional concepts, but introduces the term 'supportive' as a modification to 'premiss'. The concept of a 'persuader' is also developed. The definition is argued to capture more fully the intricacies, subtleties and rich diversity of informal arguments.
\end{abstract}

\section{Introduction}

Those entities referred to by the term 'argument' may differ in their characteristics for a number of different reasons. At the outset, the term 'argument' has at least two senses: the informal sense of 'having an argument', and the more formal sense that logicians use. Even when considering the term 'argument' in the latter sense, its exact meaning differs, depending upon the historical era, or school of thought in which logic is studied. To the lay person today, an argument (in the latter sense) is essentially a 'set of premisses that lead to a conclusion', or some similar expression. Such an understanding may be seen as symptomatic of the views popularly presented by traditional formal deductive logic today, and in recent history. Such logicians would generally agree that an ar- gument is: "any group of propositions or statements, of which one [the conclusion] is claimed to follow from the others [the premisses], which are alleged to provide grounds for the truth of that one" (Copi, 1979 ; p.2).

In relatively recent times, some logicians have recognised the grossly limited applicability of formal deductive logic to arguments as they actually occur in the "real world'. These modern logicians have sought to study the nature of arguments as they occur in the real world, and to develop methods for evaluating these arguments. Speaking very broadly, these logicians, and these goals, comprise the field of informal logic. Despite this important turn in logic, and the significant contributions made to the field, there does not appear to be any definition of the term 'argument' that is commonly referred to as the standard.

In this paper, we will propose a definition which hopefully constitutes a step forward in this endeavour, but before doing so, one important matter needs to be clarified. As alluded to above, the term 'argument' has at least two meanings. As O'Keefe $(1977 ;$ p. 121) observes, the term is sometimes used to refer to reasoning or persuasion towards a certain proposition, while on others, it is used to refer to interactions in which participants 'argue about' something (such as in a dispute). O'Keefe (1977) labels the former as 'argument, ${ }_{1}$, and the latter as 'argument, (which might also be termed 'argumentation'). To assist in plural expression, we will also refer to these as 'type 1 arguments' and 'type 2 arguments', respectively. 
O'Keefe (1982) warns that logicians must differentiate between the two types of argument if progress is to be made in theory and research (p.23). Interestingly, an examination of the informal logic literature (both in journals and textbooks) reveals a mix of definitions of type 2 arguments (e.g. van Eemeren and Grootendorst, 1982; van Eemeren and Grootendorst, 1987; and Walton, 1990), and type 1 arguments (e.g. Barry, 1980; Moore and Parker, 1986). Although it is not difficult to identify these definitions as being of these types (if familiar with the work of O'Keefe), there is nevertheless a lack of labelling of these definitions.

As previously mentioned, we are concerned with the task of defining an argument. Following the recommendation of O'Keefe (1982), we shall be more explicit and indicate here that our focus of concern in this paper is with defining type 1 arguments. In the context of type 1 arguments, O'Keefe (1982) draws a distinction between the making of an argument, and the argument itself, seeing this as analogous to the act of promising, and the actual promise itself, respectively (p. 12). Accordingly, we shall further make explicit our intent to focus on type 1 arguments themselves, rather than the making of type 1 arguments. In other words, we will be focussing upon the components or structure of the argument (or, by analogy, the 'promise'). This, however, cannot be undertaken without a consideration of factors associated with the making of an argument-in particular, we cannot entirely avoid discussion of argument function or purpose, which, in fact, is an essential consideration. One final clarification that needs to be made is that we are only concerned with arguments as produced, not as received or analysed.

At this point, the reader may wonder why we have focussed upon type 1 arguments. We believe that it is more useful, initially, to define type 1 arguments, because, as $\mathrm{O}^{\prime}$ Keefe (1982) notes, type 1 arguments may be employed in type 2 arguments (p.10). This, of course, is not surprising. If, for example, two people are disputing some claim (i.e. they are having a type 2 argument), it seems intuitively common for people to provide support for their position on the matter (i.e. they are employing type 1 arguments). Thus, type 1 arguments may be found by themselves, or in type 2 arguments. From this perspective, they seem to be the most useful type of argument to consider (although from other perspectives, type 2 arguments might be regarded as more significant).

It should be noted, though, that this enterprise of proposing definitions is one which O'Keefe (1982) regards as problem atic since definitions "typically have sharp edges that include or exclude disputable cases" (p,6). O'Keefe prefers to examine "paradigm cases" of arguments, these being examples which, by general consensus, are regarded as arguments. Whilst acknowledging the difficulties that $\mathrm{O}^{\prime}$ Keefe speaks of, we see a great need for informal logic to produce a definition.

One reason for this is that there does not appear to be any established standard definition, as mentioned. Another reason, which we see as much more significant, is that we believe the existent definitions to be quite unsatisfactory (which may itself contribute to the failure of informal logic to develop a standard definition). In this paper, we contend that there are some significant components of everyday arguments which have either not been recognised, or not fully dealt with in the existent definitions of type 1 arguments. We shall now examine those elements whilst formulating a new definition which we hope to be suitably all-encompassing of the subtleties and complexities of the structure of single units of type 1 arguments.

It is our contention that a suitable definition should consider two matters. The first of these is that the definition should indicate the criterion by which the presence or absence of an argument may be judged. As shall be seen, this cannot be 
achieved without a consideration of the function of an argument. The second matter is that a suitable definition should contain a relatively complete description of the elements of an argument. Some time will now be spent addressing the first of these issues.

\section{The Purpose of Argument}

The first matter to recognise is that, ultimately, arguments stem from a human source. Consistent with this point are two observations made by Brockriede (1975): "arguments are not in statements, but in people" (p.179), and, "argument is a human process" (p.179). It should also be readily acknowledged that few aspects of human cognition and behaviour are without purpose, and we maintain that arguments are no exception. So, for what purpose(s) do arguments exist? It is proposed here that an argument has one of two possible broad purposes: to establish, or to persuade; each of these purposes having different possible aspects.

The concept of arguments having the purpose of establishing is not something new, being central to formal deductive logic. Toulmin (1958) notes that "arguments are produced for a variety of purposes" (p.12), but then explicitly indicates that he will focus on arguments that seek to support assertions, or, as he also says, to establish conclusions (Toulmin, 1958; p.97). Interestingly, Toulmin (1958; p.12) regards this purpose as the primary function of arguments, and regards other functions as parasitic upon this use. More recently, Fogelin (1978; p.35) and Kahane (1984; p.43) both (indirectly) indicate that arguments may have the purpose of offering support for conclusions. Many other informal logicians have given similar accounts of the purpose of arguments, albeit indirectly.

When Perelman and Olbrechts-Tyteca (1969) wrote their significant treatise on argumentation, they took a different approach to Toulmin altogether. Although they are concerned with broader issues than of interest here, they devote their monograph to argumentation whose goal (or purpose) is to "secure ... adherence to the thesis presented" (p.6), More specifically, they consider argumentation that employ techniques "which use language to persuade and convince" (p.8). In fact, Perelman and Olbrechts-Tyteca (1969; p.10) urge logicians to add to their studies the type of argument they consider in their treatise. Quite clearly, this work is in great contrast with Toulmin, although when he observed that there are a number of purposes for which arguments exist, he may have been allowing for purposes such as persuasion. Perelman and OlbrechtsTyteca (1969) are not alone, though. Kahane (1971) built this purpose of persuasion into his definition of an argument, stating that an argument is the "use of language or pictures intended to persuade anyone of anything" (p.1).

These works seem to be consistent with our view that two of the purposes of arguments are to establish, or to convince. To some logicians, however, the claim that arguments can exist to establish is a contentious one. The objection is that arguments are produced for the persuasion of other people, and that there cannot be any other reason why a person would produce an argument. This view, we believe, can be attributed to the fact that it is difficult to find examples of arguments which purely seek to establish a conclusion-at leastproduced arguments of this type. We note parenthetically that there are a great many internal arguments (or mental 'self-arguments') which seek to establish conclusions, for example, a person might establish conclusions relating to how trustful a person is, or how to best organise a holiday. Nevertheless, we maintain that there are instances of produced arguments which are intended to establish-if one looks thoroughly enough.

One example could be found during a friendly and not-particularly-competitive 
game of chess in which one player (A) muses aloud as to what the best move is. The player might verbalise his/her current thinking processes in the following way: 'I must protect my one remaining knight...that's my priority...so I'd better take the bishop, because he'll cause trouble later on with my knight'. Here, player A has had the purpose of establishing a conclusion (what the best move is). No intent to persuade need be present. It needs to be remembered that this situation was one in which current thinking processes are being verbalised, without any foreknowledge of the conclusion. In any case, player A may not have cared what player B thought about the move and whether it was wise or not. This summarises our point: to say that all arguments are intended to persuade is a very strong claim, and allowance has to be made for the fact that arguments simply may be intended to establish a conclusion without any intent to persuade another person towards that conclusion.

Are there any purposes for argument besides establishing or persuading? On the basis of an examination of the various purposes for which arguments exist, we suggest that this is not the case, and that any other purposes for argument are simply aspects of these two purposes. This is by no means a categorical statement; it simply seems to be the case, as shall be illustrated below.

What are some of these 'other' purposes for which arguments exist? One possible purpose of an argument may be described as seeking to logically demonstrate the acceptability of a proposition, for example, a teacher may logically demonstrate how a certain formula (such as a law of physics) can be derived from an accepted formula on the basis of a series of mathematical manipulations. In other words, the teacher's purpose is to arrive at (or establish) a conclusion on the basis of other propositions for the benefit of his/her students. The students may very well accept the teacher's authority (or the 'Truth' of laws of physics) and accept the equation, yet wonder how it could be arrived at. The teacher may know (or believe) that the students fully accept the formula, and hence has no intention of persuasion, but simply to reason towards the equation on the basis of other known, accepted equations. It is the link that is of interest, not the acceptability of the conclusion. This is an example of a produced argument resulting from an intention purely to establish a conclusion on the basis of other propositions-a previously known conclusion.

Another possible purpose could be to check the acceptability of a proposition, for example, a mechanic may check the truth of a proposition which states that there is a fault in a certain component of a car. The mechanic may establish whether this proposition may be accepted (without actually testing the component), by arguing that if the component is faulty, then the car should exhibit certain symptoms, and since (for example) the car isn't exhibiting those symptoms, then the component cannot be faulty. Again, this may be regarded as establishing whether or not a proposition is true by examining the logical implications of that proposition (which is similar to the method of indirect proof in formal logic).

Although this might take the form of a 'self-argument', it could be produced during an apprenticeship test. Hence, the apprentice may determine whether the proposition is true or not, using stated information about the symptoms of the car, and by presenting the associated hypothetico-deductive reasoning used. Here, it does not seem proper to consider that persuasion is taking place, or likely to take place, particularly if the apprentice mechanic is unsure of the correctness of the answer that has been arrived at. The intention is purely to establish a conclusion. This, again, is an example of a produced argument resulting from an intention purely to establish a conclusion-except this time, the conclusion is initially unknown. 
What other purposes of arguments may there be? Taking a different perspective, there may be occasions in which a person uses an argument in order to reinforce a view the listener is already persuaded towards. This may be regarded as an aspect of persuasion in the sense that it involves persuasion towards a greater level of acceptance or commitment.

There may very well be other aspects of arguments not covered here, but we suspect that the purposes for which arguments exist can be reduced into one of two primary types: to establish, or to persuade. Having said this, we entirely accept the observation of van Eemeren and Grootendorst (1987) that an arguer might also have a secondary purpose when putting forward an argument, for example, to be seen as intelligent, or likeable (p.5).

\section{The Role of Intention}

Since the source of arguments is, ultimately, human, it must be recognised that intention or purpose is the criterion which decides whether an argument exists or not. The following example illustrates this point. A speaker may assert a general proposition, then state a case consistent with that general statement, for example "The service at the local department store is excellent. I went in there yesterday, and was asked three times if I needed help".

An argument analyst may recognise this as an example of the fallacy of hasty generalisation; arguing towards a general proposition on the basis of one case. Should the observer do so, he/she is possibly making an error. The speaker may have been providing the case as an example of the general statement, without any intention of producing a reasoned argument towards that proposition on the basis of that case-especially if both the speaker and listener share agreement with the originally stated proposition.
This example may be seen as an example of the False Charge of Fallacy, as described by Kahane (1984; p.121); however, there is more to the example than this. Unless more is known about the 'psychology' of the speaker, there arises a very disturbing question: was an argument even put forward? In this case, the question may only be answered by determining whether or not there was any intention to establish or persuade. If there was such an intention, then an argument exists, if not, then some other form of communication was involved - at least, from the speaker's point of view. It must be noted that regardless of the speaker's intention, a recipient might very well interpret an utterance as an argumenthowever, as stated before, this paper is not concerned with the issue of when and how communication is received as an argument.

Determining intention or non-intention, then, is an essential first step before analysing a speaker's communication as an argument (although, of course, this may be extremely difficult in some instances). As a pre-condition to defining an argument, it is proposed that:

An argument has been put forward when there has been an intention to either establish a proposition, or persuade one or more people to accept a propositionwhere such an acceptance would involve $a$ change in belief, strength of belief, or a change in behaviour.

This should not be taken as part of the definition of an argument; it is merely a precondition which must be fulfilled before it makes sense to define the elements involved when putting forward an argument. The criterion stated here has omitted any reference to an arguer, for the reason that there are circumstances in which it does not seem appropriate to speak of an arguer, for example, television advertisements: the intention of the advertisement is to persuade (if one accepts this kind of anthropomorphism).

While the notion of intention is important in the context of determining whether an argument has been put forward, it 
should be noted that it is also important in analysing the content of an argument, since some people are poor communicators and effort may be needed to understand the intended content (although, again, this may prove difficult, especially with regard to the issue of charitable interpretation).

As an aside to the current discussion, it is possible that another reason for the inability of informal logic to have established a standard definition of the term 'argument' is because there has not been any explicit mention of the conditions under which an argument exists, which, we argue, is the starting point of a satisfactory definition.

Originally, it was asserted that a suitable definition for an argument should consider two matters. The first of these was that the definition should indicate the criterion by which the presence or absence of an argument may be judged. Having spent some time on this matter, our attention will now be directed towards the second proposed requirement: that a suitable definition should contain a relatively complete description of the elements of an argument.

\section{The Verbal and Non-Verbal Elements of Argument}

In very broad terms, there are two classes of elements of arguments. The first of these are verbal elements by which we intend to include spoken or written material). The second class of elements are nonverbal. In general, the latter elements have received scant attention by logicians. One exception is that of Willard (1990) who presents a theory of argument from an interactional perspective. In his text, Willard observes that "arguers, like communicators, use any or all of the communication vehicles available to them: serial predication, claiming, and reason-giving, as well as proxemic, paralinguistic, gestural, and facial cues" (p.92). Although Willard notes that these non-verbal aspects of communication are relevant to argument analysis (p.110), he says little else, apart from providing some illustrations of the involvement of non-verbal components in arguments.

Accordingly, we shall now address this issue more fully, within the context of our current purpose. We propose that the nonverbal components of arguments may be divided into two types: those relating to the arguer, and those independent of the arguer.

\section{Non-verbal elements of argument that} relate to the arguer

This type of non-verbal component of argument relates to the popularly conceived notion of non-verbal communication. According to the well-known psychologist Argyle (1975), "speech is accompanied by an intricate set of non-verbal signals" (p.7), of which the sender (or receiver) may or may not be aware. Hence, if an argument is spoken, it may be claimed that an argument has these nonverbal elements.

These non-verbal signals may be divided into two types of signals: those that are linked to speech (such as timing, pitch, and emphasis), and those that are independent of speech (Argyle, 1975; p.7). It is worth noting here that it may be possible for a written argument to involve non-verbal elements-for example, effects of emphasis created by bold type. According to Argyle, some of the main non-verbal signals independent of speech are facial expression, gaze, gestures and bodily movements, posture, bodily contact, spatial behaviour, and aspects of appearance (pp.211-343). These elements assume that the speaker is present.

Such non-verbal messages are important, since "the impact of words is weaker and less direct than the impact of non-verbal signals" and also because they "are less well controlled and therefore more likely to be genuine" (Argyle, 1975; p.362). The latter is especially significant, since this 
implies that non-verbal signals in spoken arguments can convey the true intent and meaning of the verbal content of an argument. Further, Argyle indicates that "many sentences are ambiguous without the prosodic signals [timing, pitch, and emphasis] indicating what meaning is intended" (Argyle, 1975; p.156).

\section{Non-verbal elements of argument} independent of the arguer

We contend that there is another group of elements that may be involved in an argument which may be regarded strictly as non-verbal, but in a different sense to above. Such elements do not relate to the characteristics of the arguer in the same manner as described above (such as the person's voice, body movements, etc.). Thus, for example, a person may be presented with the visual stimulus of a graph or table in order to support a point. While other sensory stimuli are possible elements of an argument, we suspect that visual stimuli comprise the largest group of nonverbal elements of an argument that are independent of an arguer.

In seeking to provide a relatively complete description of the elements of an argument, we may now shift to a finer level of examination. Given that arguments are put forward in order to persuade or establish, one question logically suggests itself: to persuade or establish what? The answer, of course, is: other propositions, in the form of conclusions.

\section{Conclusions: \\ Prescribed Actions and Assertions}

Conclusions may be generally regarded as the end point or goal of an argument. During the first author's research into psychological aspects of argument, it was noticed that conclusions seem to relate either towards prescribed action, or towards assertions. Assertions may relate to facts, values, opinions, feelings, and so on.
Conclusions which relate to prescribed actions are 'should' conclusions, for example, that the new abortion pill should be taken off the market, or that criminals should be made to redress the harm they have done. In each case, the conclusion prescribes an action. Assertions taking the form of facts may state that certain actions have taken place, or will take place, but not that they should take place.

Depending on the purpose of the arguer, it seems that certain types of conclusions may be found. When an arguer has the purpose of persuading, both types of conclusions may be found: a person may seek to persuade someone to accept an assertion, or, a person may seek to persuade someone to carry out some action (i.e. the conclusion is one which prescribes action).

When an arguer has the purpose of es tablishing a conclusion, the arguer may establish an assertion, but it does not seem possible to establish a prescribed action, since such conclusions are the province of persuasion: such arguments seek to change a person in some way.

The next question which may be asked is: how does an arguer achieve his or her purpose? Usually, one of the answers to this question is that one or more 'premisses' are used.

\section{"Persuaders"}

It only takes a quick sampling of informal logic texts or journal articles to see that informal logicians generally use the term 'premisses' when referring to the starting point of an argument. Quite probably, this term has been imported from traditional formal logic. This term seems to be quite useful and satisfactory; however, when arguments are studied in their natural habitat, the term 'premisses' seems inadequate. This point may be demonstrated by an examination of the following example: "Couldn't you bring Tim's mark for maths up to a pass? You've always been a good 
friend of the family, and you know the financial difficulties we have in supporting him through his studies".

If it is accepted that the intention of the speaker is to argue towards the mark adjustment (hence satisfying the necessary pre-condition for an argument), then it would seem that the 'premisses' are as follows: first, the teacher (presumably) is a friend of the speaker's family, and second$1 y$, the speaker has financial difficulty in supporting Tim in his studies.

This analysis, however, seems to be incomplete. Most informal logicians would probably agree that a proportion of the force of the argument comes from an appeal to pity and to friendship. It seems reasonable to expect that the speaker is hoping that the teacher will pass the student out of (elicited) pity for the speaker's financial difficulties, and out of an (elicited) sense of 'duty' as a friend. These emotional forces in the argument are obviously not stated, yet it seems indisputable that they provide some, if not most, of the force of the argument. These 'premisses' (if they can be termed this) are, in a sense, invisible: they arise out of the stated components of the argument. In examples such as this, and many others, the term 'premisses' seems to be inadequate.

This difficulty with the term 'premiss' teaches an important lesson. If informal logic uncritically imports terminology from the formal logic tradition, then it risks being constrained in its outlook in the same way that formal deductive logic is. If informal logic is to consider arguments of a greatly different substance and complexity to formal deductive logic, then it must not allow itself to be shackled by the terminology of formal logic. We believe that the term 'premiss' is limiting informal logic, and that some additional term needs to be introduced.

Accordingly, it is suggested here that the term persuader be introduced into informal logic. A persuader may be defined as a psychologically manipulative technique used by an arguer with the intention or hope of increasing the chances of the conclusion being accepted by a recipient. The term 'technique' was used here to include methods and strategies of persuasion. In addition, the term 'technique' does not limit persuaders to verbal elements. At this point, the reader is reminded of the suggestion made earlier that the elements of arguments may be divided into those that are verbal, those that are non-verbal which relate to the arguer, and those that are non-verbal which are independent of the arguer. We maintain here that persuaders may involve any of these classes of elements.

\section{Verbal persuaders}

The existence of verbal persuaders needs little illustration (hereafter, we use the term 'verbal' in a manner that includes written text). The presence of verbal persuaders is quite clear in the example above of the 'pass-mark' argument. Judging by the fallacies identified by informal logicians, the most frequent verbal elements of persuaders involve an attempt to elicit one or more emotions in a listener, such as pity (Michalos, 1970, p.51), respect for authority (Beardsley, 1950, p.134), security of tradition (Fearnside and Holther, 1959, p. 89), fear (Ehninger, 1974, p.119), flattery (Runkle, 1981, p.299), envy (Pirie, 1985, p.58), and so on.

Non-verbal persuaders which relate to the arguer

As alluded earlier, persuaders may not be verbal, and may relate to the arguer. These may be either linked to speech, or independent of speech. Some examples of those linked to speech are as follows. First, an arguer may use a confident tone of voice in order to lend greater effect to an argument (Michalos, 1970; p.36). Another example is of a public speaker using a ridiculing laugh in an argument which seeks to dismiss a proposition (Fearnside and Holther, 1959; pp.122-124). While the 
reader might not regard these elements as part of an argument on first thought, we emphasise that if they are deliberately used by an arguer with the intention or hope of increasing the chances of the conclusion being accepted by a recipient, then they form part of the intended persuasive force of the argument.

Non-verbal aspects of persuaders that are independent of speech may include using a forlorn facial expression, hoping to elicit pity. An arguer may use certain types of gazes, such as a direct glare, in order to elicit fear, hoping that this will cause the receiver to comply with a direction. Further, an arguer may use his or her posture in order to increase the chances of occasioning persuasion-by increasing apparent physical size (to induce fear), for example. As mentioned by Argyle, aspects of appearance are also non-verbal signals, hence, a person may wear a suit to assist in persuasion, by eliciting (it is hoped) confidence in the listener that he/she is an 'authority', or some similar idea. Obviously, instances of the above persuaders (or any type of persuader) in isolation cannot be regarded as arguments; it is merely being suggested here that they may comprise part of an argument. Further, it must be emphasised that while an arguer may not deliberately use such persuaders, it may nevertheless still have an effect on the recipient. This issue becomes important when defining an argument as received, rather than from an arguer's point of view, as is of concern here.

These examples are in no way exhaustive, but are offered to illustrate the involvement of these non-verbal elements which are related to the arguer. It should be emphasised here that regardless of the elements involved in a persuader, the force of a persuader is not a property of those elements, but is a property of the effects of those elements, for example, the effect on a person of being referred to as a 'good friend of the family".

\section{Non-verbal persuaders independent} of the arguer

As discussed earlier, stimuli independent of an arguer can be used in arguments. We maintain that visual elements comprise the largest group of this type of persuader, but we allow for other sensory stimuli. Kahane (1971) is one writer who recognised the role of visual images in arguments when he defined an argument as "the use of language or pictures intended to persuade anyone of anything" (p.1). Here, 'pictures' may be taken to be an example of visual images.

Examples of visual images in persuasion are not difficult to find; they are prolific in advertisements. Thus, for example, a bedding manufacturer may depict an attractive, cosy setting for a new mattress, cigarette companies may present scenes of young people laughing and enjoying themselves at the beach, smoking a certain brand of cigarette, and so on. Such visual images may be considered to be persuaders if the advertisers employed them as techniques which were intended or hoped to increase the chances of the viewer or reader accepting the conclusion (that he/she should purchase one of the mattresses, or that he/she should smoke a particular brand of cigarette).

When these two types of non-verbal persuaders are considered, they seem to involve an attempt to elicit one or more emotions in a listener, just as verbal persuaders appear to. Accordingly, we suggest this to be the primary mechanism of effect of persuaders, but we believe this issue should not be foreclosed.

It should be emphasised here that a persuader was defined as a psychologically manipulative technique used by an arguer with the intention or hope of increasing the chances of the conclusion being accepted by a recipient. This clause places strict rules on what may be considered to be a persuader or not: there must be a deliberate intent. This is not to say, however, that a person may be influenced by elements not intended by an arguer to have an effect. 
Although we have specified that an element of an argument is a persuader if there is a deliberate intent on the part of the arguer, we acknowledge that on some occasions, there are other dimensions of intention which need to be explored. For example, a manager may decide to wear a suit as a general practice, in order to increase his/her professional image, hoping to acquire more business. During any one interaction with a potential client, this intention may not be present (the manager has become accustomed to wearing a suit, for example). Thus, in any one instance, the suit may not be 'used' with the deliberate intention of assisting in persuasion. We maintain, however, that the notion of deliberate intent remains a workable and widely useful concept. Advertisers, for example, spend considerable time planning how to best manipulate the potential consumer. To explore some of the further dimensions of deliberate intent, though, is beyond the scope of this paper.

The term 'persuader' is not intended to replace the term 'premiss'; it is merely proposed as a necessary additional term. Nevertheless, the very fact that persuaders are not limited to verbal means has important implications for informal logic-in particular, its popular use of the term "premiss".

\section{"Supportives"}

The term 'premiss' has connotations of verbal components of arguments (probably a carry-over from formal deductive logic). Yet an examination of arguments in their natural habitat indicates how the use of this term can limit informal logic: 'premisses' may take other forms, for example, they may be visual, in that graphs, tables, or charts may be used in supporting an argument. These visual images differ to those used in persuaders in that they provide support for a conclusion. Further to this, the reader is reminded again of the three suggested elements of arguments: those that are verbal, those that are non-verbal which relate to the arguer, and those that are non-verbal which are independent of the arguer.

We maintain that premisses may take the form of only two of these elements: verbal elements, and non-verbal elements which are independent of the arguer. The existence of verbal premisses needs no comment. How may premisses be comprised of non-verbal elements independent of an arguer? As indicated before, these elements are sensory stimuli. Thus, they may be visual (for example, tables and graphs), or, more interestingly, they may involve other senses, for example, taste, or of smell (for example, in seeking to demonstrate to a person that one wine is better than another, some statement may be made to that effect, and, to support that assertion, the person is provided with a sample to smell and taste).

To avoid the misleading connotations of the term 'premiss', we suggest that the term supportive be used instead; a supportive being a reason or item of information presented in an argument which is intend. ed to provide support for a conclusion. Here, an 'item of information' may include visual images such as charts, diagrams, graphs, symbols, pictures, photos, or any other stimuli which are provided by an arguer in order to establish a conclusion.

It should be noted here that it is entirely possible, if not usual, for an arguer to use supportives and persuaders in an argument: a person may provide reasons for a certain conclusion, but also induce the listener into anger, for example, in order to persuade him/her that something must be done about teenage binge drinking.

This leads us to another point. We propose that arguments intended to persuade may be characterised as existing at some point on a continuum: some arguments only use supportives (at one end of the scale), and others only use persuaders (at the other end); however, the majority of arguments intended to persuade may be 
located between the two extremes, using a mix of supportives and persuaders to different degrees. It may be wondered how an argument intended to persuade may only use supportives. This is because the arguer may be attempting to persuade a person by 'logical reasoning' alone.

On the other hand, arguments which are intended purely to establish only employ supportives. If persuaders are used, then the argument is not intended to establish, but to persuade.

At this point, the reader may regard the introduction of the term 'supportive' as being a rather draconian step, thinking that it would be better to re-define the term 'premiss'. One drawback of this approach is that it may take too long for the 'amended' definition to become commonplace. The advantage of introducing the term 'supportive' is that it commands a more instant requirement for adjustment. The issue of whether this terminological change should take place is not the aim of the current discussion; it is merely offered as a possible solution, in contrast to re-defining the well-engrained term of 'premiss'.

How else does an arguer achieve his or her purpose of persuading or establishing propositions? This question is perhaps best asked in terms of whether there is anything else involved in the production of an argument. The answer is, of course, that arguments involve assumptions. These components of arguments are less obvious than supportives or persuaders, but are nevertheless involved in the production of an argument, and hence must be included in a satisfactory definition of the components of an argument.

\section{Consciously and Unconsciously Used Assumptions}

Informal logicians have used a variety of terms to describe assumptions: hidden premisses, unstated premisses, unstated assumptions, tacit premisses and so on; all essentially referring to the same aspect of arguments.

Interestingly, Gough and Tindale (1985; p.100) prefer the term 'hidden premisses' compared to the term 'missing premisses', because the former implies (properly) that there is something present (albeit unstated), whereas the latter implies there is something actually missing from the argument (in the sense that it does not exist at all, in any way).

One further point made by Gough and Tindale (1985) is that hidden premisses should be distinguished from assumptions. They regard assumptions as underlying beliefs that an arguer is either unaware of, or regards as "too obvious or commonplace to mention explicitly" (p.100). They explain further that "often the hidden premiss is simply an unstated point, integral to the argument, but not at all an assumption in the sense defined above" (p.100).

Ennis (1982) draws an important distinction between 'used' assumptions and 'needed' assumptions. The latter are not of relevance in defining the term 'argument', since, as Ennis indicates, they are the assumptions needed to make an argument a good one, and a person "might need a particular proposition, but not use it in a piece of reasoning" (Ennis, 1982; p.63). In contrast, used assumptions are those "unstated reasons that a person actually use[s] ... as a basis of argument" (p.63).

Since our aim is to define the components of a produced argument, it must be emphasised that needed assumptions are of no interest or relevance here (although they are important in argument evaluation). This is because needed assumptions may not be part of a produced argument. Only the used assumptions are (which may also be needed, but this is not the point).

Although Ennis provides a perfectly satisfactory definition of the term 'assumption', a little more may be said about the term. A used assumption may be regarded as any unstated component of an argument that can be expressed in propositional form 
that an arguer uses in the course of attempting to persuade or to establish (apart from, of course, non-verbal aspects of supportives or persuaders). In response to the point made by Gough and Tindale (1985) above, we suspect that there may be difficulties in delineating hidden premisses from assumptions (if indeed there is a difference). We maintain that the important issue is that assumptions (as we shall call them) are those elements used in the course of an argument, as outlined above.

Assumptions, then, may be straightforward factual matters, for example, if a person argues that "John won't pass because he didn't attend all the practical classes", the person could very well have used the assumption that "A person must attend all practical classes to pass the course".

Assumptions may also be more complex, and less easily expressible in propositional form, for example, morals, attitudes and values. To illustrate, a person may present the following Gambler's fallacy to a friend: "You've won by throwing four 3's of the dice in a row now, so I suggest that you leave it at that, because your chance of throwing another 3 is considerably less now than before". If it is accepted that the person has the intention of trying to persuade his/her friend to stop gambling (to fulfill the criterion for being an argument) then it seems reasonable to suspect that the person has "made" (or used) the assumption that losing money is an undesirable event (or something similar), and, that the gambler does not wish to lose money.

The arguer in the above example may be unaware of using these particular assumptions, especially the former, since it is such an ingrained value in most people. This raises the question of whether or not an arguer is conscious of his or her assumptions. The authors" view is that there are two types of assumptions that may be used while producing an argument: those that an arguer is aware of ('conscious assumptions"), and those that an arguer is unaware of ('unconscious assumptions').
Examples of 'conscious' type assumptions are easy to find. In everyday argumentation, an arguer may be well aware that his/her argument uses, and rests upon, a certain assumption. In some cases, the arguer may be prepared to face criticism for 'making' that assumption by having ready evidence in support of the truth or acceptability of that assumption.

An informal examination of everyday arguments also provides some support for the concept of 'unconscious assumptions'. It is not difficult to recall instances in which a person may indicate to an arguer that he/she is operating under a certain assumption, to which the arguer responds with surprise (at being made aware of the assumption), followed by acceptance of the observation.

Whilst discussing the process of identifying assumptions in another person's argument, it must be recognised that some informal logicians have put forward a number of practical suggestions and criteria for determining an arguer's assumptions (notably, Scriven (1976) and Ennis (1982), amongst others). Other informal logicians, however, have been critical of this practical advice, particularly van Eemeren and Grootendorst (1982), van Eemeren and Grootendorst (1983), Burke (1985) and also Gough and Tindale (1985). Hitchcock (1985) discusses some wider issues in the nature of enthymematic arguments. The reader is referred to these sources for detailed comments on assumptions in arguments. The main point being expressed here, however, is that arguments often (if not always) employ assumptions.

\section{Defining the Components of an Argument}

On the basis of the above, we argue that any suitable definition of the components of an argument should make reference to those components identified above. We may now consider the extent to which 
current treatments and definitions achieve this. Given our focus upon type 1 arguments, corresponding treatments and definitions of type 1 arguments shall be considered; however, we shall also examine some of the definitions of type 2 arguments.

One of the earliest significant treatments of the nature of informal argument was that of Toulmin (1958). Although Toulmin does not explicitly provide a definition for an argument, he attempts to provide an account of what is "involved in establishing conclusions by the production of arguments" (p.97). The components he identifies include 'data', 'warrants' and the 'backing' of warrants (pp.97-107). If Toulmin's text is examined closely, warrants and backings may be simply seen as an argument's assumptions, in that they are unstated components of an argument which may be made explicit by an arguer, on being challenged. Regardless of this issue, Toulmin's account of arguments lacks a treatment of several components of argument discussed above, including techniques of persuasion, and the variety of forms which arguments may take. These criticisms should be qualified, though, by pointing out that it was probably not his intention to address the same issues as the present discussion.

Another major treatment of the nature of informal argument, in the form of rhetoric, is the work of Perelman and OlbrechtsTyteca (1969). Although it is irrelevant here (in that they are not concerned with definitional issues), it is worth indicating that one limitation of their excellent work is their stated intention to focus on printed text, whilst neglecting the "study of delivery or oratorical effect" (p.6), which are components of argument which we have allowed for. Nevertheless, it must be stated that their impressive, mammoth work should be considered as an expansion of an enormous number of details which we do not have the room, or the need, to discuss.

Turning our attention now to actual attempts to define type 1 arguments, a 'random' sample reveals quite a remarkable degree of variation. Kahane (1971) proposed that an argument is "the use of language or pictures intended to persuade anyone of anything" (p.1). This definition is probably one of the better ones, but it lacks any reference to arguments that seek to establish or support conclusions. Thomas (1973) defines an argument as "a sentence or sequence of sentences containing statements some of which are set forth as supporting, making probable or explaining others" (p.1). This definition is lacking in the reverse manner to Kahane, in that there is no reference to arguments which seek to persuade.

According to Barry (1980), "an argument is any group of propositions (true or false propositions) one of which is said to follow from the others" (p.5). This definition suffers from a similar problem as Thomas', but makes the further error of limiting 'supportives' (as they might be termed) to being either true or false. Most informal logicians are aware that this concept is naive: propositions in arguments possess varying degrees of 'truth', some being probable, others being only possible, and yet others cannot be evaluated as true or false because of their nature (for example, they are value laden).

More recently, Moore and Parker (1986) provide the following definition: "an argument consists of a conclusion (the claim that is argued for) and premisses (the claims that provide the readers or hearers with reasons for believing the conclusion)" (p.182). This definition may be regarded similarly to Thomas' definition, in that there is no mention of persuasion, but it also limits conclusions to claims.

The above limitations with the presented definitions are only the most basic. Each of the definitions fails to refer to the types of conclusions that may be found, the role of assumptions, and the possible involvement of non-verbal and visual means of arguing. Upon examining numerous other definitions (including sources 
dating back to 1950 which contained at least some reference to informal logic) we found similar limitations.' In general, the current definitions lack reference to the multitudinous facets of arguments which have been illuminated in our main discussion of the components of arguments.

As mentioned earlier, some definitions of type 2 arguments will now be considered, to determine whether these provide any better accounts of the components of arguments (on the assumption that these components are likely to be the same as in type 1 arguments).

One particularly meticulous treatment of type 2 arguments is that of van Eemeren and Grootendorst (1987) who propose that: "Argumentation is a social, intellectual, verbal activity serving to justify or refute an opinion, consisting of a constellation of statements and directed towards obtaining the approbation of an audience" (p.7). Although this might not be easily seen to constitute a type 2 definition, van Eemeren and Grootendorst (1987) indicate that "holding an opinion is not in itself ... sufficient to initiate argumentation: it is necessary not only that this first opinion be expressed, but also that another interlocutor should indicate that he [sic] has a different point of view" (pp.3-4).

Van Eemeren and Grootendorst (1987) are relatively vague in specifying what the components of argumentation are, apart from an expressed opinion, and "a constellation of one or more statements by means of which a language user tries to justify or refute an opinion" (p.5). In answer to our earlier question, this definition provides no improvement on the definitions considered thus far, due to its lack of specificity. To be fair, though, it seems likely that it was not the intention of van Eemeren and Grootendorst to provide a definition of the nature we are concerned with.

One of the most recent type 2 definitions is proposed by Walton (1990) who states that "an argument is a social and verbal means of trying to resolve, or at least contend with, a conflict or difference that has arisen or exists between two (or more) parties. An argument necessarily involves a claim that is advanced by at least one of the parties" (p.411). Walton's definition is lacking in a similar manner to that of van Eemeren and Grootendorst's, although the same qualifying conditions also need to be made when evaluating Walton's definition.

On the basis of the noted deficiencies of current definitions of the components of arguments (particularly the more relevant type 1 definitions), a new definition of the components of a type 1 argument will be proposed here. Before doing so, it is worth re-stating our proposed criterion by which the presence or absence of an argument may be judged:

An argument has been put forward when there has been an intention to either establish a proposition, or persuade one or more people to accept a proposition (where such an acceptance would involve a change in belief, strength of belief, or a change in behaviour).

We further propose the following definition of the components of an argument:

The object-matter of an argument's intention (to establish or persuade) is its conclusion. A conclusion will be either a prescribed action, or an assertion, and this conclusion may or may not be stated. Attempts to achieve an argument's intention will involve the use of at least one supportive and/or at least one persuader (but cannot solely employ non-verbal persuaders), and these attempts may involve consciously or unconsciously used assumptions.

This definition should be considered as co-existent with the criteria proposed before, since, as originally stated, we believe that a suitable definition of an argument should state the conditions under which arguments are produced, and, it should provide a relatively complete specification of the components of those arguments.

Most of this definition stands by itself; however, some additional comment is necessary. The definition indicates that 
conclusions may or may not be stated. This clause was included so as to allow for the fact that arguments sometimes take the form of a single sentence, which, in a context, has the purpose of arguing towards a certain conclusion, although that conclusion is never stated. Thus, in a debate about abortion, an anti-abortionist may simply state: "Abortion denies the foetus the right to live".

This example also illustrates the need for the criteria of intention: if the intention of this person was to persuade an opponent that abortion should be opposed, then an argument has been put forward-towards that unstated conclusion. In cases such as this, the context provides the conclusion. Another advantage of the proposed definition is apparent here: it caters for the subtle forms that arguments may take, which sometimes bear no resemblance to the traditional format of an argument, as exemplified above. It should also be noted that this definition also accepts the standard formal deductive concept of an argumentas long as intention is present (to establish).

The next part of the definition requires some elaboration. The definition next stated that attempts to achieve an argument's intention will involve the use of at least one supportive and/or persuader. Importantly, it was specified that an argument cannot solely employ non-verbal persuaders. Implicitly, we allow for non-verbal supportives being used solely, but not non-verbal persuaders.

How may the former take place? Consider the following example: a speaker states that "Our business is in financial trouble", and then, without saying a word, displays a chart showing profit declining into debt over the last year. The speaker allows the audience to view the chart, then proceeds to talk about some possible solutions. In this case, the conclusion has been stated, and a non-verbal supportive (the chart) is provided as the only supportive. Assuming intent to persuade (for example) on the part of the speaker, this counts as an argument, according to our definition.
On the other hand, if a person holds a knife to someone's throat, and says "Give me your money", this does not count as an argument. It might be said that the "conclusion" (stated) is essentially one of prescribed action for the victim, and it might be said that the person has the intent of persuading the victim to hand over his or her money, but since a nonverbal persuader (the knife, inducing fear) is the sole means of attempting to persuade the person, this example does not count as an argument. It must be acknowledged here that there becomes a point at which mere opinion determines what an argument is, and to some extent, our definition at this point is reflecting this; however, our discussions with colleagues indicates general agreement that instances such as the above do not count as arguments.

Another aspect of the definition needing comment is the assertion that used assumptions may be involved. This itself presents no difficulty; however, we strongly suspect that all arguments contain used assumptions (whether consciously or unconsciously)-primarily because of the concept of pre-suppositions, as considered by Ennis (1982). According to Ennis, presuppositions which underlie referential definite descriptions "assume that there exists an object to which the speaker thinks that he or she is referring", while presuppositions underlying attributive definite descriptions assume "that there exists an object fitting [a] description" (p. 79). It seems impossible for an argument to not refer to objects (or persons) in this way, and hence, it seems impossible for an argument to not involve assumptions in the form of these pre-suppositions. Further, it seems difficult to contemplate an argument not involving some other more general kind of underlying assumption. Safety, however, forces us to simply assert that assumptions may be involved,

We maintain that the main strengths of the definition are its 'two-part' format, and 
the fact that it attempts to be as flexible and all-encompassing as possible, without being too vague and general, nor too detailed. The definition caters for a wide variety of arguments which previously might not have been considered arguments. It also rules out instances which may previously have been regarded as existing within a doubtful 'grey area', such as the example of the person demanding money using a knife.

Another advantage of the definition is that it could very well make diagramming of arguments considerably easier, for the purposes of analysis. In particular, there is no reason why persuaders cannot be written down in a similar manner to supportives, for example: 'patriotism elicited', 'fears for safety of children elicited', 'mattress made more appealing by using a cosy, nice setting', and so on. Under the usual type of definitions considered, diagramming of these elements of an argument would be difficult, if not impossible.

Are there any limitations with the definition? One apparent problem with defining an argument in the above manner is that informal logicians have also studied 'extended arguments', as termed by Johnson and Blair $(1980 ;$ p.17). Such arguments often possess complex structures of sub-arguments used in putting forward main arguments, and so on. Such 'extended arguments' are not really a difficulty for the definition, since they may be considered as comprising single unit arguments, whose conclusions may be used as supportives of other 'higher-order' arguments.

Further, persuaders used in single unit arguments may have a combined effect that operates as a persuader for a higherorder argument. Assumptions may be used in a manner particular to the higher-order argument, or they may be used in the arguments whose conclusions are used as supportives, hence the assumptions in a higher-order argument may be traced back to a contributing argument. Thus, a complex web of unit arguments may be found in some circumstances, each existing at different hierarchies, sometimes overlapping.

One deliberate limitation with the definition is that it, strictly speaking, only covers arguments which are presented. In our earlier discussion of purposes for which arguments exist generally, we referred to the case of a mechanic engaging in reasoning within his or her own mind. Such arguments we referred to as "selfarguments', Our definition does not apply to such arguments.

Another limitation with our definition is that it may be regarded as an 'arguerdriven' definition, in that it defines an argument from the perspective of the arguer. This brings with it some practical limitations. The first part of the definition described the criterion for judging whether or not an argument has been put forward: intention. While this is a strength of the definition, it is also a weakness, in a practical sense, since the argument analyst cannot always determine what a person's intentions are (with certainty, at least). Neither can an argument analyst always completely and accurately determine the components of the argument.

\section{Arguments as Perceived}

The above practical 'limitation' motivates the introduction of the concept of a 'received argument'. Arguments are rarely, if ever, presented in isolation; they are usually read or heard. Generally speaking, if a person perceives another as having the purpose of arguing towards a certain conclusion, using certain (perceived) means, then an argument has been put forward-from the recipient's perspective; irrespective of whether the other person had any such intention. Further, the perceived means may not correspond to those actually used by an arguer. Time will not be spent discussing the components of a perceived argument, as they may involve any of the components already discussed. 
This concept is of critical importance in two areas of concern: argument analysis, and understanding the dynamics of argumentation. In terms of argument analysis, it is important to realise that it is the received argument that is analysed, and this may not exactly match the produced argument. A recipient may perceive another as having produced an argument, when in fact no such argument was put forward, or even vice versa. Even if an argument is put forward, the perceived means used in arguing towards the conclusion may be different to the means actually used or intended by the arguer.

These possibilities are illustrated in the following example: a newspaper article may report that since the new lord mayor came into office, crime has increased significantly. One person reading this may regard the item as arguing that the lord mayor was responsible for this increase because the crime followed the commencement of the new lord mayor's office (in other words, the reader may perceive that a causal argument has been put forward). Another person reading the article may not regard there to be any such argument, but simply a statement of an unfortunate turn of events for the lord mayor to deal with.

In the first case, the reader perceived the writer as having the intention of arguing that the lord mayor was responsible for the increase in crime, because the crime increased soon after the mayor took up office. In the second case, no such intention was attributed to the writer. Thus, the way in which a recipient perceives certain material will determine whether the recipient regards the presentation as an argument or not. The nature of this perception will also probably decide whether evaluative thinking is applied to what the recipient is presented with (whether it be acceptance or non-acceptance).

Although not illustrated in the above example, there is great potential for discrepancies to be found between the means actually used by an arguer, and the means perceived by a recipient. One only needs to observe the number of instances of errors in human communication to realise the potential for a such a mis-match.

The concept of the received argument is also of critical importance in understanding the dynamics of argumentation. It should be emphasised here again that it has been our intent to focus on the nature of a single unit argument, rather than the wider issues of argumentation. Such issues are examined in great depth by Perelman and Olbrechts-Tyteca (1969), amongst others, to which the reader is referred. Nevertheless, the concept of the received argument does have relevance to the dynamics of argumentation: an argument may be presented to a recipient, who receives the argument. The recipient may (correctly) perceive that an argument has been put forward, and will respond. The nature of that response will be a function of the argument as perceived. If the perceived argument differs from that actually produced, the result may take the form of an innocent Straw Person attack (based on a mismatch of perceived and actual positions on a matter).

At this point, it is clear that the term 'argument' needs to be examined from the point of view of the receiver as well as the arguer. Although the purpose of this paper was to define the term 'argument' from the arguer's perspective, such a treatment would have been lacking if attention were not drawn to the concept of the 'received argument'. Needless to say, this topic requires greater treatment than afforded here, as a subject in its own right. ${ }^{2}$

In the meantime, our definition of the term 'argument' (from the arguer's perspective) is presented here for consideration. It seems at least useful, if not essential, to define the subject matter of a field, or at least, part of its subject matter. It is our hope that the proposed definition is a firm step in the right direction in the complex task of defining the term 'argument'. 


\section{Notes}

This paper has benefitted greatly from comments and criticisms by Ralph $\mathrm{H}$. Johnson, J. Anthony Blair, Christopher Tindale, and an anonymous referee.

The definitions examined included: Beardsley (1950; p.9); Schipper and Schuh (1959; p.3); Angell (1964; p.5); Michalos (1970; p.2); Salmon (1973; p.3); Byerly (1973; p.13); Ehninger (1974; pp. 10-11); Pospesel (1974; p.4); Carney and Scheer (1974; p.3); Annis (1974; p.1); Baum (1975; p.4); Scriven (1976; p.55); Blumberg (1976; p.4); Munson (1976; p.176); Engel (1976; p.6); Manicas and Kruger (1976; p.42); Simco and James (1976; p.1); Carter (1977; p.2); Johnson and Blair (1977; pp.3-4); Girle, Halpin, Miller and Williams (1978; p. 31); Copi (1978; p.7); Fogelin (1978; pp.34$36)$; Weddle $(1978$; p.2); and those more recently proposed, as cited in our discussion.

2 This concept will be treated in a later paper.

\section{References}

Angell, R.B. (1964) Reasoning and logic, Appleton-Century-Crofts, New York.

Annis, D.B. (1974) Techniques of critical reasoning, Charles E. Merrill, Columbus, Ohio.

Argyle, M. (1975) Bodily communication, Methuen and Company, London.

Barry, V.E. (1980) Practical logic, Holt, Rinehart and Winston, New York.

Baum, R. (1975) Logic, Holt, Rinehart and Winston, New York.

Beardsley, M.C. (1950) Practical logic, PrenticeHall, Englewood Cliffs, New Jersey.

Blumberg, A.E. (1976) Logic, Alfred A. Knopf, New York.

Brockriede, W. (1975) "Where is argument?" Journal of the American Forensic Association 11, 179-182.

Burke, M. (1985) 'Unstated premisses' Informal Logic 7, 107-118.

Byerly, H.C. (1973) A primer of logic, Harper and Row, New York.

Carney, J.D. and Scheer, R.K. (1974) Fundamentals of logic, Macmillan, New York.

Carter, K.C. (1977) A contemporary introduction to logic with applications, Glencoe Press, Beverly Hills.

Copi, I.M. (1978) Introduction to logic, Macmillan, New York.

Copi, I.M. (1979) Symbolic logic, Macmillan, New York.
Ehninger, D. (1974) Influence, belief and argument, Scott, Foresman and Company, Illinois.

Engel, S.M. (1976) With good reason, St. Martin's Press, New York.

Ennis, R.H. (1982) 'Identifying implicit assumptions', Synthese 51, 61-86.

Fearnside, W.W. and Holther, W.B. (1959) Fallacy. The counterfeit of argument, Englewood Cliffs, Prentice-Hall, New Jersey.

Fogelin, R.J. (1978) Understanding arguments, Harcourt Brace Jovanovich, New York.

Girle, R.H., Halpin, T.A., Miller, C.L. and Williams, G.H. (1978) Inductive and practical reasoning, Rotecoge, Brisbane, Queensland.

Gough, J. and Tindale, C. (1985) "Hidden' or 'Missing' premisses', Informal Logic 7, 99-106.

Hitchcock, D. (1985) 'Enthymematic argument', Informal Logic 7, 83-97.

Johnson, R.H. and Blair, J.A. (1977) Logical self-defense, McGraw-Hill Ryerson, Toronto.

Johnson, R.H. and Blair, J.A. (1980) 'The recent development of informal logic'. In J.A. Blair and R.H. Johnson (Eds.) Informal logic. The first international symposium, Edgepress, Inverness, California.

Kahane, H. (1971) Logic and contemporary rhetoric, Wadsworth, Belmont, California.

Kahane, H. (1984) Logic and contemporary rhetoric. The use of reason in everyday life, Wadsworth, Belmont, California. 
Manicas, P.T. and Kruger, A.N. (1976) Logic: The essentials, Mc-Graw-Hill, New York.

Michalos, A.C. (1970) Improve your reasoning, Prentice-Hall, Englewood Cliffs, New Jersey.

Moore, B.N. and Parker, R. (1986) Critical thinking. Evaluating claims and arguments in everyday life, Mayfield Publishing Company, Palo Alto, California.

Munson, R. (1976) The way of words. An informal logic, Houghton Mifflin, Boston.

O'Keefe, D.J. (1977) 'Two concepts of argument', Journal of the American Forensic Association 13, 121-128.

O'Keefe, D.J. (1982) The concepts of argument and arguing. In J.R. Cox and C.A. Willard (Eds.) Advances in argumentation theory and research, Southern Illinois Press: Carbondale.

Perelman, C and Olbrechts-Tyteca, L. (1969) The new rhetoric: A treatise on argumentation, University of Notre Dame Press, Notre Dame.

Pospesel, H. (1974) Propositional logic, Prentice-Hall, Englewood Cliffs, New Jersey.

Runkle, G. (1981). Good thinking. Holt Rinehart and Winston, New York.

Salmon, W.C. (1973) Logic, Prentice-Hall, Englewood Cliffs, New Jersey.

Schipper, E.W. and Schuh, E. (1959) A first course in modern logic, Henry Holt, New York.

Scriven, M. (1976) Reasoning, McGraw-Hill, New York.

Simco, N.D. and James, G.G. (1976) Elementary logic, Dickenson, Encino, California.

Thomas, S.N. (1973) Practical reasoning in natural language, Prentice-Hall, Englewood Cliffs, New Jersey.
Toulmin, S.E. (1958) The uses of argument, Cambridge University Press, Cambridge.

Van Eemeren, F.H. and Grootendorst, R. (1982) 'The speech acts of arguing and convincing in externalised discussions', Journal of Pragmatics 6, 1-24.

Van Eemeren, F.H. and Grootendorst, R. (1982) 'Unexpected [sic] premisses: Part I', Journal of the American Forensic Association 19, 97-106.

Van Eemeren, F.H. and Grootendorst, R. (1982) 'Unexpressed premisses: Part II', Journal of the American Forensic Association, 19. 215-225.

Van Eemeren, F.H. and Grootendorst, R. (1987). Handbook of argumentation theory: A critical survey of classical backgrounds and modern studies. Dordrecht, Holland, Foris.

Walton, D.N. (1990) 'What is reasoning? What is an argument?', The Journal of Philosophy, 87 (8), 399-419.

Weddle, P. (1978) Argument. A guide to critical thinking, McGraw-Hill, New York.

Willard, C.A. (1990). A theory of argumentation. University of Alabama Press, Tuscaloosa.

\section{P. CHITTLEBOROUGH}

DEPARTMENT OF PSYCHOLOGY

UNIVERSITY OF ADELAIDE

SA 5000, AUSTRALIA

M. E. NEWMAN

ELECTRICITY TRUST OF S.A.

P.O. BOX 2567

KENT TOWN, S.A., 5067

AUSTRALIA 